\title{
Preface: advances in cichlid research IV: behavior, ecology, and evolutionary biology
}

\author{
Stephan Koblmüller (D) R. Craig Albertson • Martin J. Genner • \\ Kristina M. Sefc • Tetsumi Takahashi
}

Received: 28 May 2021 / Revised: 28 May 2021 / Accepted: 10 June 2021 / Published online: 1 July 2021

(C) The Author(s), under exclusive licence to Springer Nature Switzerland AG 2021

With currently 1,727 valid species, naturally distributed from southern North America to southern South America, across most of Africa, in southern, Madagascar, and the Indian sub-continent, cichlid fishes (Cichlidae) are among the most species rich fish families (Fricke et al., 2021). Considering that the mostly endemic cichlid fish assemblages in the East African lakes alone include approximately 2,000 species (including described and undescribed species) (Turner et al., 2001; Salzburger et al., 2014), it might well be that this fish family is indeed the most speciose of all. This enormous species richness is also reflected

Guest editors: S. Koblmüller, R. C. Albertson, M. J. Genner, K. M. Sefc \& T. Takahashi / Advances in Cichlid Research IV: Behavior, Ecology and Evolutionary Biology.

S. Koblmüller $(\square) \cdot$ K. M. Sefc

Institute of Biology, University of Graz, Universitätsplatz

2, 8010 Graz, Austria

e-mail: stephan.koblmueller@uni-graz.at

\section{R. C. Albertson}

Department of Biology, University of Massachusetts,

Amherst, MA 01003, USA

\section{J. Genner}

School of Biological Sciences, University of Bristol, Bristol BS81TQ, UK

T. Takahashi

Institute of Natural and Environmental Sciences,

University of Hyogo, Sanda 669-1546, Japan in a morphological, behavioral, and ecological diversity, and it is this immense variety of form and function within a single fish lineage that has fascinated researchers since the end of the nineteenth century (e.g., Steindachner, 1875; Boulenger, 1898), such that cichlids are now considered a prime model system in evolutionary biology research (e.g., Salzburger, 2018). A multitude of publications on cichlids has advanced not only our understanding of what underlies the diversification of this exceptional fish family, but also our knowledge of the evolution of biological diversity in general.

The current special issue is the fourth in a series of special issues published in Hydrobiologia exclusively devoted to cichlid research and presents a collection of 15 papers that focuses on various aspects of cichlid behavior, ecology, conservation, evolutionary biology, paleontology, parasitology, and genomics. We are happy to share this exquisite collection of cichlid research papers with the readers of Hydrobiologia. Below, the papers are briefly summarized in the order in which they appear in this special issue.

\section{A fossil cichlid radiation}

The cichlid fossil record is tremendously important for our understanding of cichlid evolution. For certain parts of the cichlid tree of life, however, the fossil record is sparse, which makes putting (at least part of 
the) cichlid diversification in a temporal context a difficult endeavor. Until recently, we lacked suitable fossils for calibrating the tree of the species rich Lake Tanganyika radiation, which also gave rise to the ancestors of the megadiverse radiations in the other East African Great Lakes and some lineages restricted to rivers and smaller lakes (Koblmüller et al., 2008). With the discovery and description of $\uparrow$ Tugenchromis pickfordi Altner et al. 2017, a reliable calibration point became available (Altner et al., 2017) and has been used to obtain robust divergence time estimates for the Lake Tanganyika radiation (Irisarri et al., 2018; Ronco et al., 2021). In this issue, Altner \& Reichenbacher (2021) present, based on a large number of largely well-preserved upper Miocene fossils, a small radiation from paleolake Waril in Central Kenya. These fossils not only provide an additional calibration point for the Lake Tanganyika radiation, but also give insights into patterns of phenotypic diversity in this ancient radiation. Interestingly, the species of this ancient radiation mainly differ in tooth shape, suggesting that they have coexisted in the palaeolake by utilizing different food items, as seen in some extant crater lakes (e.g., Schliewen et al., 1994; Geiger et al., 2010). This finding lends further support to the idea that niche partitioning according to feeding resources is an important driver of diversification in cichlid radiations.

\section{Lake Tanganyika cichlids—-targeting the patterns and origin of phenotypic and behavioral variation}

Lake Tanganyika is the oldest of the East African Great Lakes (Cohen et al., 1993) and thus harbors the morphologically, behaviorally, ecologically, and genetically most diverse cichlid species assemblage (Snoeks, 2000). Several publications in this special issue target specific questions regarding morphological variation and incipient speciation, as well as the causes and consequences of variation in intra-specific color patterns in Lake Tanganyika cichlids.

A hallmark of cichlid radiations are shifts in feeding architecture. While this dimension of cichlid diversity is most striking at macroevolutionary levels (e.g., Cooper et al., 2010), subtle shifts between sister taxa and/or close ecological competitors can reveal important dynamics in cichlid ecology and evolution (e.g., Herler et al., 2010; Van Steenberge et al., 2018;
Conith et al., 2020). In this issue, Kerschbaumer et al. (2021) compare the shapes of various bones of the head in species of Tropheus Boulenger, 1900 that are either the sole occupant at a locality in Lake Tanganyika or co-occur with another Tropheus species. They documented subtle but significant differences in bone shapes between Tropheus species, between populations of the same species, and, importantly, between sympatric and non-sympatric species, offering a nuanced view of the ecological pressures that may be acting on specific elements of the feeding apparatus.

Divergent morphological traits might also be an indication of incipient speciation. Together with Telmatochromis dhonti (Boulenger, 1919) and $T$. brachygnathus Hanssens \& Snoeks, 2003, T. temporalis Boulenger, 1898 forms a complex of closely related, morphologically similar and often sympatric species (Ronco et al., 2021). Notably, within $T$. temporalis, distinct morphotypes have been described that occur in sympatry or parapatry but have different habitat preferences, leading to reproductive isolation (Takahashi, 2004, 2010; Takahashi et al., 2009; Winkelmann et al., 2017). Thus, the T. temporalis complex is considered a good model system for studying ecological speciation. Here, Takahashi (2021) reports another morphologically and genetically distinct morph, 'slender', within this complex. This morph inhabits deeper waters than the parapatric 'normal' morph. Very likely, ecological factors may have caused reproductive isolation between the various T. temporalis morphs, as seen in some crater lake cichlid pairs (Barluenga et al., 2006; Malinsky et al., 2015).

Body coloration of cichlids plays important roles in intra- and interspecific interactions (Maan \& Sefc, 2013). In the polychromatic Astatotilapia burtoni (Günther, 1893), male coloration is correlated with social status, aggressive behavior and physiological characteristics, with possible effects on dominance hierarchies and mating success (Korzan et al., 2008). In this issue, Whitaker et al. (2021) examine yet another corollary of color differences, namely conspicuousness to predators and the associated variation in escape behavior. They find that conspicuousness to conspecifics-useful in intraspecific signalingcomes along with elevated conspicuousness to predators, but also with compensatory anti-predatory responses. The authors suggest that covariation of 
visual conspicuousness and predation avoidance contributes to the maintenance of the alternative color phenotypes.

Variation in color pattern, specifically in the size of carotenoid-colored patch, was also implicated in dominance relationships among females of the Kaiser cichlid, Tropheus sp. "Ikola" (sensu Ziegelbecker et al., 2018). In this issue, Ziegelbecker et al. (2021) investigate the underlying mechanisms and report weak support for an intimidating effect of large color patches and for correlations with exploratory behavior. Strikingly, concentrations of integumentary carotenoids were remarkably high not only in the yellowcolored skin (which was expected), but also in the surrounding, black skin. This suggests that the allocation of carotenoids to visual signaling is not particularly costly in this species and sheds doubts on whether patch size can carry information on individual quality and condition.

The variety of social and mating systems found in cichlids offers promising opportunities for research into the processes that drive or facilitate behavioral diversification. The review by Lein \& Jordan (2021) focuses on the study of cognitive and social evolution, identifies methodological challenges and terminological difficulties experienced in the field, and highlights the value of a particular clade of cichlids, the shelldwelling Lamprologini of Lake Tanganyika, to address existing research gaps. The auspicious study system is characterized by diverse and highly developed social and cognitive capacities in a background of a shared habitat and morphological similarity. The availability of robust phylogenetic reconstructions and the amenability to field and laboratory work are additional assets of this emerging model system.

\section{Lake Victoria cichlids-novel sex determination system}

African cichlids have emerged as a powerful model to understand the evolution of sex determination mechanisms, owing to their extreme diversity of sex determiners and rates of sex determination turnover (Gammerdinger \& Kocher, 2018; Gammerdinger et al., 2018; Böhne et al., 2019). Feller et al. (2021) take a genetic mapping approach to the discovery of additional mechanisms in these fishes. Using three different interspecific crosses of haplochromine cichlids from Lake Victoria they identified several sex determining chromosomes, including one that had not previously been recognized. Remarkably, this new sex chromosome was found to represent, in a speciesspecific manner, either the male heterogametic XY or the female heterogametic ZW system of sex determination. This paper adds to the growing body of literature on the high evolvability of sex determination in cichlids.

\section{Invasive tilapias in East Africa-interactions between invasive and native species}

With increasing use of cichlid fishes in aquaculture globally, particularly tilapia of the genus Oreochromis Günther, 1889, there is an increased risk of their establishment in non-native habitats (Canonico et al., 2005). While negative effects on the native fish faunas have been documented, there is still relatively little understanding of the ecological or behavioral mechanisms that lead to changes in native fish biodiversity. Champneys et al. (2021) contribute to our understanding of this problem by studying the behavioral interactions between Manyara tilapia Oreochromis amphimelas (Hilgendorf, 1905), a species endemic to alkaline lakes of central Tanzania, and Nile tilapia Oreochromis niloticus (Linnaeus, 1758) which has invaded those water bodies (Shechonge et al., 2019). They found evidence that the invasive Nile tilapia were more aggressive than native Manyara tilapia in size-matched trials over the limited resource of shelter. This resulted in competitive dominance of Nile tilapia, potentially reducing fitness of the native species. These results provide rare empirical support for interference competition as a potential mechanism leading to native fish biodiversity decline upon arrival of invasive tilapia species.

It is also possible that invasive species influence native fish faunas through exploitative (resource) competition for food, with invasive species efficiently utilizing limited dietary resources resulting in a fitness disadvantage of native species (Britton et al., 2011). Dieleman et al. (2020) studied the potential for resource competition between native and invasive tilapia in Lake Chala, which is on the border between Tanzania and Kenya. Here, two invasive species are now abundant, Oreochromis cf. korogwe (LoweMcConnell, 1955) and Coptodon rendalli (Boulenger, 
1897), and there are signs of the endemic Chala tilapia Oreochromis hunteri Günther, 1889 being in decline (Moser et al., 2019). Through a longitudinal study of diet using stomach content analysis and stable isotope ratios of carbon $\left(\delta^{13} \mathrm{C}\right)$ and nitrogen $\left(\delta^{15} \mathrm{~N}\right)$, the authors found all three species to be primarily herbivorous, feeding on both benthic and planktonic food sources, and overlapping substantially in diet. However, Dieleman et al. also provide evidence for seasonal dietary differences among species, with native Chala tilapia feeding on dry season phytoplankton blooms. Thus, although resource competition between native and invasive species for limited food resources may occur in this system, it is also possible that this competition is periodically reduced due to partitioning of seasonally abundant resources.

\section{West African cichlids-clarifying some systematic issues in a difficult cichlid tribe}

Even though Central and West African river systems are less species rich then the spectacular cichlid radiations in the East African Great Lakes, they harbor a stunning taxonomic range of taxa, and only recently research has started to focus on patterns and processes underlying this diversity (e.g., Schwarzer et al., 2012, 2015; Dunz \& Schliewen, 2013). One cichlid lineage comprising mainly Central and West African taxa, the tribe Hemichromini, has been largely ignored by researchers in the recent past. The tribe includes only two genera, Anomalochromis Greenwood, 1985 and Hemichromis Peters, 1858, the latter of which can be subdivided into two phenotypically distinct groups, the so-called jewel cichlids, which are popular aquarium fish, and the larger five-spotted Hemichromis species. Within the two Hemichromis groups, taxonomy and systematics are still unclear and a matter of debate. Bitja-Nyom et al. (2021) took an integrative approach, combining morphological and genetic data, to revise the group of five-spotted Hemichromis. Their comprehensive analyses suggest synonymy of Hemichromis frempongi Loiselle, 1979, with Hemichromis fasciatus Peters, 1858, but splitting Hemichromis elongatus (Guichenot, 1861) in two species, $H$. elongatus and the newly described Hemichromis camerounensis Bitja-Nyom et al. (2021), thus clarifying some of the pending questions in this taxonomically notoriously difficult cichlid genus.

\section{South American cichlids-new insights into their visual system}

Cichlid species have undergone extensive diversification in visual systems, and there is now substantial evidence of selection on visual opsins driving divergence in spectral sensitivity (Trezise \& Collin, 2005). A focus of the research on the evolution of cichlid visual systems has been on species in the African Great Lakes Tanganyika, Malawi and Victoria (e.g., Spady et al., 2005; Sugawara et al., 2005; Terai et al., 2006; Nandamuri et al., 2017). However, increasingly, attention is directed on the evolution of visual systems in Neotropical cichlids (Weadick et al., 2012; Escobar-Camacho et al., 2017; Torres-Dowdall et al., 2017; Härer et al., 2018, Hauser et al., 2021). Here, Fabrin et al. (2021) compare the strength of directional selection on the longwave sensitive (LWS) opsin gene in African and Neotropical cichlids. They found evidence for positive selection most prominent in African cichlids, but with some noteworthy signals of selection operating on the same nucleotide positions in both systems. The results suggest strong potential for future comparative research using the power of both African and Neotropical radiations to explore the links between selection, gene expression, and local visual environments.

\section{Cichlid parasites}

Parasites are strong drivers of natural selection, and over recent years there have been several studies investigating links between ectoparasite faunas and cichlid diversification (Raeymaekers et al., 2013; Vanhove et al., 2015; Gobbin et al., 2020a). While the parasite faunas of wild-caught fish were found to differ between closely related species, it has been unclear whether this was due to differences in exposure related to habitat use or diet, or to intrinsic differences among species in their vulnerability to parasite taxa. Here Gobbin et al. (2020b) explored this issue in Lake Victoria cichlids, comparing the abundance of three ectoparasite taxa (two copepod species and glochidia mussel larvae) on wild and laboratorybred representatives of two closely related species of Pundamilia Seehausen \& Bouton, 1998 from Lake Victoria. They found that differences among wild fish did not persist in laboratory stocks. This key result 
suggests that variance in parasite faunas in wild fish are most plausibly due to differences in their ecology, such as diet and depth occupancy, and not necessarily selection resulting in differential immunological responses to the same parasite exposure. In general, this study highlights differential exposure as a likely driver of observed natural variation in parasite loads. However, the result does not rule out parasites as contributors to differences in the fitness of incipient species pairs occupying ecologically distinct natural environments.

Among the many taxa that parasitize on cichlid fishes, monogeneans of the genus Cichlidogyrus Paperna, 1960 are probably the most species rich. Even though we are far from knowing the whole diversity in this genus, substantial progress has been made over the last two decades in describing the species diversity and phylogenetic relationships in this genus (e.g., Mendlová \& Šimková, 2014; Vanhove et al., 2015; Kmentová et al., 2016a; Rahmouni et al., 2018). However, very little is known about intraspecific diversity of these parasite species (for an exception see Kmentová et al., 2016b). Here, Rahmouni et al. (2021) characterize morphological variation within two Cichlidogyrus species and discuss their finding in the light of different dispersal capacities of their hosts. As expected, morphological population differentiation is lower in the parasite species from the welldispersing host species, demonstrating that population genetic patterns of Cichlidogyrus is directly related to the ecology of the host species.

Parasites are not only linked to the evolution of cichlid fish species communities, they also impact biosecurity and public health. Hence, model systems enabling study of host parasite interactions are very much in need. High species richness, a direct life cycle and amenability to experimental work (Zhi et al., 2018) make Cichlidogyrus an attractive monogenean model system for parasitology and, more generally speaking, disease research. In this issue, Cruz-Laufer et al. (2021) propose the cichlid-Cichlidogyrus system as macroevolutionary model of species interactions and discuss what is needed to establish this network as model system.

\section{Genomic resources-gene editing in tilapia}

Technologies for gene editing are becoming more accessible for a wider range of organisms, opening the door for exciting new research programs aimed at dissecting the molecular genetic mechanisms that underlie biological processes across a vast array of taxa. The CRISPR/Cas9 system holds particular promise in this regard, owing to its high efficiency and straightforward methods (Knott \& Doudna, 2018). Applications of this technology to cichlids have involved both tilapiine (e.g., Li et al., 2014) and haplochromine (e.g., Juntti et al., 2016) species. As CRISPR/Cas9 gene editing becomes established in cichlid research, it will be important to standardize methods and share best practices. To this end, Li et al. (2021) provide a detailed protocol, from the selection of target sites to the screening of mutants, for CRISPR/ Cas9 in tilapia.

Acknowledgements We want to thank all the authors for their excellent contributions and all the reviewers for participating in the work on this special issue. We are particularly grateful to the journal's editor-in-chief Koen Martens, who kindly gave us the opportunity to publish this fourth special issue devoted to cichlid research in Hydrobiologia.

\section{References}

Altner, M., U. K. Schliewen, S. B. R. Penk \& B. Reichenbacher, 2017. $\uparrow$ Tugenchromis pickfordi, gen. et sp. nov., from the upper Miocene-a stem-group cichlid of the 'East African Radiation', Journal of Vertebrate Paleontology 37: e1297819.

Altner, M. \& B. Reichenbacher, 2021. A small cichlid species flock from the Upper Miocene (9-10 MYA) of Central Kenya. Hydrobiologia, doi: https://doi.org/10.1007/ s10750-020-04358-z

Barluenga, M., K. N. Stölting, W. Salzburger, M. Muschick \& A. Meyer, 2006. Sympatric speciation in Nicaraguan crater lake cichlid fish. Nature 439: 719-723.

Bitja-Nyom, A. R., J. F. Agnèse, A. Pariselle, C. F. Bilong-Bilong, A. Gilles \& J. Snoeks, 2021. A systematic revision of the five-spotted Hemichromis complex (Cichliformes: Cichlidae) from West Africa and Lower Guinea, with the description of a new species from Cameroon. Hydrobiologia. https://doi.org/10.1007/s10750-020-04506-5.

Böhne, A., A. A.-T. Weber, J. Rajkov, M. Rechsteiner, A. Riss, B. Egger \& W. Salzburger, 2019. Repeated evolution versus common ancestry: sex chromosome evolution in the haplochromine cichlid Pseudocrenilabrus philander. Genome Biology and Evolution 11: 439-458.

Britton, J. R., J. Cucherousset, J. Grey \& R. E. Gozlan, 2011. Determining the strength of exploitative competition from 
an introduced fish: roles of density, biomass and body size. Ecology of Freshwater Fish 20: 74-79.

Canonico, G. C., A. Arthington, J. K. McCary \& M. L. Thieme, 2005. The effects of introduced tilapias on native biodiversity. Aquatic Conservation: Marine and Freshwater Ecosystems 15: 463-483.

Champneys, T., M. J. Genner \& C. C. Ioannou, 2021. Invasive Nile tilapia dominates a threatened indigenous tilapia in competition over shelter. Hydrobiologia. doi: https://doi. org/10.1007/s10750-020-04341-8

Cohen, A. S., M. J. Soreghan \& C. A. Scholz, 1993. Estimating the age of formation of lakes: An example from Lake Tanganyika, East African Rift system. Geology 21: 511-514.

Conith, A. J., M. R. Kidd, T. D. Kocher \& R. C. Albertson, 2020. Ecomorphological divergence and habitat lability in the context of robust patterns of modularity in the cichlid feeding apparatus. BMC Evolutionary Biology 20: 95.

Cooper, W. J., K. Parsons, A. McIntyre, B. Kern, A. McGeeMoore \& R. C. Albertson, 2010. Bentho-pelagic divergence of cichlid feeding architecture was prodigious and consistent during multiple adaptive radiations within African rift-lakes. PLoS ONE 5: e9551.

Cruz-Laufer, A. C., T. Artois, K. Smeets, A. Pariselle \& M. P. M. Vanhove, 2021. The cichlid-Cichlidogyrus network: a blueprint for a model system of parasite evolution. Hydrobiologia. doi: https://doi.org/10.1007/s10750-02004426-4

Dieleman, J., C. Cocquyt, W. D. Nyingi \& D. Verschuren, 2020. Seasonality in diet and feeding habits of the endemic Chala tilapia (Oreochromis hunteri) and two introduced tilapiine cichlids in Lake Chala, East Africa. Hydrobiologia. doi: https://doi.org/10.1007/s10750-020-04427-3

Dunz, A. R. \& U. K. Schliewen, 2013. Molecular phylogeny and revised classification of the haplotilapiine cichlid fishes formerly referred to as "Tilapia". Molecular Phylogenetics and Evolution 68: 64-80.

Escobar-Camacho, D., Ramos, E., Martins, C. and Carleton, K.L. 2017. The opsin genes of Amazonian cichlids. Molecular Ecology 26: 1343-1356.

Fabrin, T. M. C., L. S. Gasques, R. J. da Graça, S. M. A. P. Prioli, W. J. Da Graça \& A. J Prioli, 2021. Positive selection of the long-wavelength opsin gene in South American cichlid fishes. Hydrobiologia. doi: https://doi.org/10.1007/s10750021-04611-z

Feller, A. F., V. Ogi, O. Seehausen \& J. I. Meier, 2021. Identification of a novel sex determining chromosome in cichlid fishes that acts as $\mathrm{XY}$ or $\mathrm{ZW}$ in different lineages. Hydrobiologia. doi: https://doi.org/10.1007/s10750-02104560-7

Fricke, R., W. N. Eschmeyer \& J. D. Fong, 2021. Eschmeyer's catalog of fishes: genera/species by family/subfamily. [available on internet at http://researcharchive. calacademy.org/research/ichthyology/catalog/ SpeciesByFamily.asp. Accessed on 23 May 2021].

Gammerdinger, W. J., M. A. Conte, B. A. Sandkam, A. Ziegelbecker, S. Koblmüller \& T. D. Kocher, 2018. Novel sex chromosomes in three cichlid fishes from Lake Tanganyika. Journal of Heredity 109: 489-500.

Gammerdinger, W. \& T. Kocher, 2018. Unusual diversity of sex chromosomes in African Cichlid fishes. Genes 9: 480.
Geiger, M. F., J. K. McCrary \& J. R. Stauffer, Jr., 2010. Description of two new species of the Midas cichlid complex (Teleostei: Cichlidae) from Lake Apoyo, Nicaragua. Proceedings of the Biological Society of Washington 123: 159-173.

Gobbin, T. P., M. P. M. Vanhove, A. Pariselle, T. G. G. Groothuis, M. E. Maan \& O. Seehausen, 2020a. Temporally consistent species differences in parasite infection but no evidence for rapid parasite-mediated speciation in Lake Victoria cichlid fish. Journal of Evolutionary Biology 33: 556-575.

Gobbin, T. P., R. Tiemersma, G. Leone, O. Seehausen \& M. E. Maan, 2020b. Patterns of ectoparasite infection in wildcaught and laboratory-bred cichlid fish, and their hybrids, implicate extrinsic rather than intrinsic causes of species differences in infection. Hydrobiologia. https://doi.org/10. 1007/s10750-020-04423-7.

Härer, A., A. Meyer \& J. Torres-Dowdall, 2018. Convergent phenotypic evolution of the visual system via different molecular routes: how Neotropical cichlid fishes adapt to novel light environments. Evolution Letters 2: 341-354.

Hauser, F. E., K. L. Ilves, R. K. Schott, E. Alvi, E., H. LópezFernández \& B. S. Chang, 2021. Evolution, inactivation and loss of short wavelength-sensitive opsin genes during the diversification of Neotropical cichlids. Molecular Ecology 30: 1688-1703.

Herler, J., M. Kerschbaumer, P. Mitteroecker, L. Postl \& C. Sturmbauer, 2010. Sexual dimorphism and population divergence in the Lake Tanganyika cichlid fish genus Tropheus. Frontiers in Zoology 7: 4.

Irisarri, I., P. Singh, S. Koblmüller, J. Torres-Dowdall, F. Henning, P. Franchini, C. Fischer, A. R. Lemmon, E. Moriarty Lemmon, G.G. Thallinger, C. Sturmbauer \& A. Meyer, 2018. Phylogenomics uncovers early hybridization and adaptive loci shaping the radiation of Lake Tanganyika cichlid fishes. Nature Communications 9: 3159.

Juntti, S. A., A. T. Hilliard, K. R. Kent, A. Kumar, A. Nguyen, M. A. Jimenez, J. L. Loveland, P. Mourrain, \& R. D. Fernald, 2016. A neural basis for control of cichlid female reproductive behavior by prostaglandin F2 $\alpha$. Current Biology 26: 943-949.

Kerschbaumer, M., L. Postl \& C. Sturmbauer, 2021. Microevolutionary change in viscerocranial bones under congeneric sympatry in the Lake Tanganyikan cichlid genus Tropheus. Hydrobiologia. doi: https://doi.org/10. 1007/s10750-021-04536-7

Kmentová, N., M. Gelnar, S. Koblmüller\& M. P. M. Vanhove, 2016a. First insights into the diversity of gill monogeneans of 'Gnathochromis' and Limnochromis (Teleostei, Cichlidae) in Burundi: do the parasites mirror host ecology and phylogenetic history? PeerJ 4: e1629.

Kmentová, N., M. Gelnar, M. Mendlová, M. Van Steenberge, S. Koblmüller \& M. P. M. Vanhove, 2016. Reduced hostspecificity in a parasite infecting non-littoral Lake Tanganyika cichlids evidenced by intraspecific morphological and genetic diversity. Scientific Reports 6: 39605.

Knott, G. J. \& J. A. Doudna, 2018. CRISPR-Cas guides the future of genetic engineering. Science 361: 866-869.

Koblmüller, S., K. M. Sefc \& C. Sturmbauer, 2008. The Lake Tanganyika cichlid species assemblage: recent advances in molecular phylogenetics. Hydrobiologia 615: 5-20. 
Korzan, W. J., R. R. Robison, S. Zhao \& R. D. Fernald, 2008. Color change as a potential behavioral strategy. Hormones and Behavior 54: 463-70.

Lein, E., \& A. Jordan, 2021. Studying the evolution of social behavior in one of Darwin's Dreamponds: a case for the lamprologine shell-dwelling cichlids. Hydrobiologia. doi: https://doi.org/10.1007/s10750-020-04473-x

Li, M., H. Yang, J. Zhao, L. Fang, H. Shi, M. Li, Y. Sun, X. Zhang, D. Jiang \& D. Wang, 2014. Efficient and heritable gene targeting in tilapia by CRISPR/Cas9. Genetics 197: 591-599.

Li, M., S. Dai, X. Liu, X. Xiao \& D. Wang, 2021. A detailed procedure for CRISPR/Cas9-mediated gene editing in tilapia. Hydrobiologia. doi: https://doi.org/10.1007/ s10750-020-04414-8

Maan, M. E. \& K. M. Sefc, 2013. Colour variation in cichlid fish: Developmental mechanisms, selective pressures and evolutionary consequences. Seminars in Cell \& Developmental Biology 24: 516-528.

Malinsky, M., R. J. Challis, A. M. Tyers, S. Schiffels, Y. Terai, B. P. Ngatunga, E. A. Miska, R. Durbin, M. J. Genner \& G. F. Turner, 2015. Genomic islands of speciation separate cichlid ecomophs in an East African crater lake. Science 350: 1493-1498.

Mendlová, M. \& A. Šimková, 2014. Evolution of host specificity in monogeneans parasitizing African cichlid fish. Parasites \& Vectors 7: 69.

Moser, F. N., J. van Rijssel, B. Ngatunga, S. Mwaiko \& O. Seehausen, 2019. The origin and future of an endangered crater lake endemic; phylogeography and ecology of Oreochromis hunteri and its invasive relatives. Hydrobiologia 832: 283-296.

Nandamuri, S. R., M. R. Yourick \& K. L. Carleton, 2017. Adult plasticity in African cichlids: Rapid changes in opsin expression in response to environmental light differences. Molecular Ecology 26: 6036-6052.

Raeymaekers, J. A. M., P. I. Hablützel, A. F. Grégoir, J. Bamps, A. K. Roose, M. P. M. Vanhove, M. Van Steenberge, A. Pariselle, T. Huyse, J. Snoeks \& F. A. M. Volckaert, 2013. Contrasting parasite communities among allopatric colour morphs of the Lake Tanganyika cichlid Tropheus. BMC Evolutionary Biology 13: 41.

Rahmouni, C., M. P. M. Vanhove \& A. Šimková, 2018. Seven new species of Cichlidogyrus Paperna, 1960 (Monogenea: Dactylogyridae) parasitizing the gills of Congolese cichlids from northern Lake Tanganyika. PeerJ 6: e5604.

Rahmouni, C., M. Van Steenberge, M. P. Vanhove \& A. Simková, 2021. Intraspecific morphological variation in Cichlidogyrus (Monogenea) parasitizing two cichlid hosts from Lake Tanganyika exhibiting different different dispersal capacities. Hydrobiologia. doi: https://doi.org/10. 1007/s10750-020-04429-1

Ronco, F., M. Matschiner, A. Böhne, A. Boila, H. H. Büscher, A. El Taher, A. Indermaur, M. Malinsky, V. Ricci, A. Kahmen, S. Jentoft \& W. Salzburger, 2021. Drivers and dynamics of a massive adaptive radiation in cichlid fishes. Nature 589: 76-81.

Salzburger, W., B. Van Bocxlaer \& A. S. Cohen, 2014. Ecology and evolution of the African Great Lakes and their faunas. Annual Review of Ecology, Evolution, and Systematics 45, 519-545.
Salzburger, W., 2018. Understanding explosive diversification through cichlid fish genomics. Nature Reviews Genetics 19: 705-717.

Schliewen, U. K., D. Tautz \& S. Pääbo, 1994. Sympatric speciation suggested by monophyly of crater lake cichlids. Nature 368: 629-632.

Schwarzer, J., B. Misof \& U. K. Schliewen, 2012. Speciation within genomic networks: a case study based on Steatocranus cichlids of the lower Congo rapids. Journal of Evolutionary Biology 25: 138-148.

Schwarzer, J., A. Lamboj, K. Langen, B. Misof \& U. K. Schliewen, 2015. Phylgoeny and age of chromidotilapiine cichlids (Teleostei: Cichlidae). Hydrobiologia 748: 185-199.

Shechonge, A., B. P. Ngatunga, S. J. Bradbeer, J. J. Day, J. J. Freer, A. G. P. Ford, J. Kihedu, T. Richmond, S. Mzighani, A. M. Smith, E. A. Sweke, R. Tamatamah, A. M. Tyers, G. F. Turner \& M. J. Genner, 2019. Widespread colonization of Tanzanian catchments by introduced Oreochromis tilapia fishes: the legacy from decades of deliberate introduction. Hydrobiologia 832: 235-253.

Snoeks, J., 2000. How well known is the ichthyodiversity of the large East African lakes? Advances in Ecological Research 31: 17-38.

Spady, T.C., O. Seehausen, E. R. Loew, R. C. Jordan, T. D. Kocher \& K. L. Carleton, 2005. Adaptive molecular evolution in the opsin genes of rapidly speciating cichlid species. Molecular Biology and Evolution 22: 1412-1422.

Steindachner, F., 1875. Beiträge zur Kenntniss der Chromiden des Amazonenstromes. Sitzungsberichte der kaiserlichen Akademie der Wissenschaften 71: 61-137.

Sugawara, T., Y. Terai, H. Imai, G. Turner, S. Koblmüller, C. Sturmbauer, Y. Shichida \& N. Okada, 2005. Parallelism of amino acid changes at the RH1 affecting spectral sensitivity among deep-water cichlids from Lakes Tanganyika and Malawi. Proceedings of the National Academy of Sciences USA 102: 5448-5453.

Takahashi, T., 2004. Morphological and genetic distinctness of rock and shell-bed dwelling Telmatochromis (Teleostei, Cichlidae) in the South of Lake Tanganyika suggest the existence of two species. Journal of Fish Biology 65: 419-435.

Takahashi, T., 2010. Different degrees of lunar synchronization of ovary development between two morphs of a Tanganyikan cichlid fish. Hydrobiologia 644: 139-143.

Takahashi, T., 2021. A new morph of Telmatochromis temporalis (Cichlidae; Cichliformes) from Lake Tanganyika. Hydrobiologia. doi: https://doi.org/10.1007/s10750-02004433-5

Takahashi, T., K. Watanabe, H. Munehara, L. Rüber \& M. Hori, 2009. Evidence for divergent natural selection of a Lake Tanganyika cichlid inferred from repeated radiations in body size. Molecular Ecology 18: 3110-3119.

Terai, Y., O. Seehausen, T. Sasaki, K. Takahashi, S. Mizoiri, T. Sugawara, T. Sato, M. Watanabe, N. Konijnendijk, H. D. Mrosso \& H. Tachida, 2006. Divergent selection on opsins drives incipient speciation in Lake Victoria cichlids. PLoS Biology 4: e433.

Torres-Dowdall, J., M. E. Pierotti, A. Härer, N. Karagic, J. M. Woltering, F. Henning, K. R. Elmer\& A. Meyer, 2017. Rapid and parallel adaptive evolution of the visual system 
of Neotropical Midas cichlid fishes. Molecular Biology and Evolution 34: 2469-2485.

Trezise, A. E. \& S. P. Collin, 2005. Opsins: evolution in waiting. Current Biology 15: R794-R796.

Turner, G. F., O. Seehausen, M. E. Knight, C. J. Allender \& R. L. Robinson, 2001. How many species of cichlid fishes are there in African lakes? Molecular Ecology 10: 793-806.

Van Steenberge, M., J. A. M. Raeymaekers, P. I. Hablützel, M. P. M. Vanhove, S. Koblmüller \& J. Snoeks, 2018. Delineating species along shifting shorelines: Tropheus (Teleostei, Cichlidae) from the southern subbasin of Lake Tanganyika. Frontiers in Zoology 15: 42.

Vanhove, M. P., A. Pariselle, A., M. Van Steenberge, J. A. Raeymaekers, P. I. Hablützel, C. Gillardin, B. Hellemans, F. C. Breman, S. Koblmüller, C. Sturmbauer, J. Snoeks, F. A. M. Volckaert \& T. Huyse, 2015. Hidden biodiversity in an ancient lake: phylogenetic congruence between Lake Tanganyika tropheine cichlids and their monogenean flatworm parasites. Scientific Reports 5: 13669.

Weadick, C. J., E. R. Loew, F. H. Rodd \& B. S. Chang, 2012. Visual pigment molecular evolution in the Trinidadian pike cichlid (Crenicichla frenata): a less colorful world for neotropical cichlids? Molecular Biology and Evolution 29: 3045-3060.
Whitaker, K. W., M. Alvarez, T. Preuss, M. E. Cummings \& H. A. Hofmann, 2021. Courting danger: socially dominant fish adjust their escape behavior and compensate for increased conspicuousness to avian predators. Hydrobiologia. doi: https://doi.org/10.1007/s10750-020-04475-9

Winkelmann, K., L. Rüber \& M. J. Genner, 2017. Lake level fluctuations and divergence of cichlid fish ectomorphs in Lake Tanganyika. Hydrobiologia 791: 21-34.

Ziegelbecker, A., F. Richter \& K. M. Sefc, 2018. Colour pattern predicts outcome of female contest competition in a sexually monomorphic fish. Biology Letters 14: 20180480.

Ziegelbecker, A., K. Remele, H. W. Pfeifhofer \& K. M. Sefc, 2021. Wasteful carotenoid coloration and its effects on territorial behavior in a cichlid fish. Hydrobiologia. doi: https://doi.org/10.1007/s10750-020-04354-3

Zhi, T., X. Xu, J. Chen, Y. Zheng, S. Zhang, J. Peng, C. L. Brown \& T. Yang, 2018. Expression of immune-related genes of Nile tilapia Oreochromis niloticus after Gyrodactylus cichlidarum and Cichlidogyrus sclerosus infections demonstrating immunosuppression in coinfection. Fish \& Shellfish Immunology 80: 397-404.

Publisher's Note Springer Nature remains neutral with regard to jurisdictional claims in published maps and institutional affiliations. 